\title{
O centenário de Ignácio Rangel
}

\author{
JOSÉ MARIA DIAS PEREIRA*
}

In February 2014, celebrating the centenary of Ignácio Rangel — one of the most original thinkers of the Brazilian economy. This article aims to summarize the main points of his work, considering that his theoretical contribution is poorly known of the new generations. It was one of the first to associate the internal cycles of our economy to the cycles of the world economy through the thesis of duality. Inflation was part of the "syndrome of the recession." Out of recession, there should be transfer of resources from activities with idle capacity for latecomers sectors, in case public services.

Keywords: Ignácio Rangel; economic cycles; inflation and recession.

JEL Classification: E31; E32; E61.

\section{INTRODUÇÃO}

O economista Ignácio de Mourão Rangel nasceu no Maranhão, em 20 de fevereiro de 1914, e faleceu, no Rio de Janeiro, em quatro de março de 1994. Portanto, em 2014, comemora-se o centenário do nascimento do grande mestre. Falecido aos 80 anos, Rangel foi, segundo o próprio jornal que noticiou o seu falecimento, "um dos mais importantes analistas econômicos do país" ${ }^{1}$. Mas Rangel foi muito mais do que isso. Formado em Direito, aprendeu Economia na prática, participando da assessoria econômica do $2^{\circ}$ governo Vargas, onde colaborou para a criação da Petrobras e Eletrobras. Em 1956, foi trabalhar no BNDES, participando da elaboração do Plano de Metas do governo de Juscelino Kubitschek.

\footnotetext{
* Doutor em Economia pela Universidade Federal de Pernambuco (UFPE). Professor adjunto aposentado da Universidade Federal de Santa Maria (UFSM) e professor do curso de Ciências Econômicas do Centro Universitário Franciscano, em Santa Maria (RS). E-mail: pereirajm@uol.com.br. Artigo baseado em capítulo do livro Centenário de Ignácio Rangel, edição conjunta da Universidade Federal do Maranhão e Conselho Regional de Economia do Maranhão, 2014.

1 “Economista Ignácio Rangel morre no Rio”, Folha de São Paulo, 5/3/1994.
} 
Foi também um entusiasta da industrialização do país, fazendo parte, desde o início, do Instituto Superior de Estudos Brasileiros (ISEB) — núcleo acadêmico que abrigava os teóricos do nacional-desenvolvimentismo. Rangel colaborou com universidades, como a Unicamp e UFMG, e participou de órgãos de classe, tendo sido presidente de Conselho Regional de Economia do Rio de Janeiro.

Rangel se destacou ainda como um teórico extremamente original da Economia, expondo suas ideias através de vários livros e artigos em periódicos e jornais. Um desses periódicos foi justamente a Revista de Economia Política, fundada em 1981 por um grupo de economistas que rejeitava a visão dominante da economia, como ciência positiva e neutra, e defendia um retorno às suas origens clássicas, como "Economia Política". Rangel destacou-se, desde o primeiro número, como um dos mais frequentes colaboradores e mereceu a honra de ver o seu nome como patrono da revista, ao lado de Caio Prado Jr. e o de Celso Furtado.

Tomei conhecimento da teoria da inflação de I. Rangel, por ocasião da elaboração da minha dissertação de mestrado (Pereira, 1984), defendida na Universidade Federal do Rio Grande do Sul (UFRGS), ao pesquisar a influência da alimentação na inflação brasileira nos anos 1970. Na época (início dos anos 1980), o regime militar já "fazia água" e o debate sobre as causas da inflação assumia um contorno claramente ideológico entre estruturalistas (esquerda) e monetaristas (direita). O livro A inflação brasileira, de I. Rangel, que havia sido recentemente (1978) reeditado, abria uma nova perspectiva de interpretação da inflação, com ênfase na estrutura concentrada de comercialização de produtos agrícolas. Em 1982, quando Rangel deu uma palestra na UFRGS, por ocasião do lançamento do seu livro Ciclo, tecnologia e crescimento, conheci-o pessoalmente.

Cerca de uma década depois, quando fazia meu doutoramento, na Universidade Federal de Pernambuco (UFPE), no Recife, Rangel fez uma espécie de "miniconferência" para os estudantes da Pós-Graduação. Foi daí que surgiu a ideia de escrever uma "comunicação" sobre os 30 anos da $1^{a}$ edição do seu livro A inflação brasileira, publicada pela Revista de Economia Política (v. 3, n. 13, jul.-set./1993). Meu derradeiro encontro com I. Rangel se deu cerca de um ano antes de seu falecimento, numa palestra na Universidade Federal de Santa Maria (UFSM). Com a saúde debilitada, Rangel falava com dificuldade, mas com o entusiasmo de sempre. Deixou um legado de valor inestimável, mas infelizmente pouco reconhecido. Além do propósito de homenagear o grande mestre pelo centenário do seu nascimento, o autor deste artigo pretendeu também divulgar suas principais ideias entre as novas gerações de economistas.

\section{ESQUERDA OU DIREITA?}

Dentre os traços da personalidade marcante de Ignácio Rangel, o que mais fascinava era a sua capacidade crítica. Seria injusto não classificá-lo como um 
homem de esquerda ${ }^{2}$, mas, em determinado momento, foi rejeitado pela esquerda como sendo de direita. Isso é especialmente verdadeiro quando, nos anos $1950 \mathrm{e}$ 1960, discordou da tese da esquerda de que a reforma agrária era uma "précondição" para o desenvolvimento. Rangel argumentava, na época, que não havia condições objetivas para a realização de uma reforma agrária no Brasil, mas que isso, em absoluto, inviabilizaria a retomada do crescimento econômico. Mesmo após o encerramento do ciclo de crescimento dos anos 1970, quando passou a defender a reforma agrária, continuou a ser alvo da incompreensão da esquerda ${ }^{3}$.

Sua visão sobre desenvolvimento ia além das ideologias de esquerda e direita. $\mathrm{Na}$ trilha de Keynes e Kalecki, colocava o investimento como condição fundamental para o desenvolvimento. Considerando a condição do Brasil como país periférico, a princípio, propôs que o Estado bancasse o financiamento ao investimento. Com a crise das finanças públicas dos anos 1960, sugeriu ao ministro da Fazenda do primeiro governo militar a criação da correção monetária como estratégia alternativa para manter os investimentos. Posteriormente - sendo este mais um exemplo do pragmatismo de Rangel —, em face das distorções causadas pela correção monetária, no final dos anos 1970, sugeriu a criação de uma nova lei de concessão de serviços públicos. Através dela, o setor privado passaria a encarregar-se, de forma crescente, pelos investimentos públicos de infraestrutura. Essa sugestão não deixa de ser surpreendente, considerando que Rangel teve um papel importante na criação de grandes empresas estatais brasileiras, como a Petrobras e a Eletrobras. Nem em sonhos Rangel poderia imaginar que, após o seu falecimento (1994), a privatização de empresas estatais iria tão longe.

No que se refere à inflação, foi a mesma coisa. Advogado por formação, o único curso formal de economia que Rangel frequentou foi, nos anos 1950, na Comissão Econômica para a América Latina e Caribe (CEPAL), templo do estruturalismo latino-americano, no Chile. Nem por isso, Rangel poupou o estruturalismo na sua análise das causas da inflação brasileira. No clássico A inflação brasileira, publicado no limiar do regime militar (1963), Rangel ironizava os "nossos ortodoxos estruturalistas" por confundirem a estrutura concentrada de intermediação - causa principal da alta do preço dos alimentos - com inelasticidade da oferta agrícola. Igualmente, não poupava os "nossos ortodoxos monetaristas" por não se darem conta que a moeda é passiva, ou seja, é o aumento de preços que

\footnotetext{
${ }^{2}$ Segundo Maria da Conceição Tavares, Rangel "foi o grande patrono dos chamados economistas de esquerda" (Folha de São Paulo, 5/3/1994).

${ }^{3}$ Numa crônica publicada no Jornal do Brasil, em 18/9/1979, reclamava da assessoria econômica de Miguel Arraes que continuava criticando-o por ser contra a reforma agrária quando, há muito, havia mudado de opinião. Escreveu ele: "Em matéria de assessoramento econômico, nossa esquerda é, em geral, uma catástrofe [...]. Ora, Miguel Arraes não constitui exceção. Sua assessoria não aprendeu nada, nem esqueceu nada, nestes três lustros [...] Só faltaria que, agora, em 1979, quando eu estou sustentando que isso (tese contrária à reforma agrária como précondição para o desenvolvimento) não é mais verdade, eles levantem a bandeira do meu velho livro (refere-se ao livro A questão agrária brasileira), para afirmar aquelas verdades tornadas caducas. Não seria essa a primeira vez” (Rangel, 1982b, p. 156).
} 
leva as autoridades monetárias a aumentarem a quantidade de moeda e não o contrário.

Não é difícil imaginar que, não se filiando a nenhuma corrente dominante de economistas de esquerda ou de direita, Rangel fosse, com raras exceções, solenemente ignorado por ambos os lados. Em certo momento, deixou transparecer alguma mágoa em relação a isso ${ }^{4}$. O que poucos perceberam é que Rangel tinha maior autonomia de voo. Ambicionava construir uma teoria dos ciclos da economia brasileira que não fosse simplesmente reflexo das vicissitudes das economias do centro capitalista desenvolvido. Para chegar até ela, baseou-se nas teorias dos ciclos longos (50 anos) do russo N. Kondratieff e dos ciclos médios (10 anos) do francês C. Juglar. Do ponto de vista da teoria econômica, foi buscar subsídios em Marx, em Keynes e em Schumpeter ${ }^{5}$, dentre outros. Surgia, assim, a tese da dualidade da economia brasileira.

\section{CICLOS E DUALIDADE}

A tese da dualidade, segundo Bielschowsky (1996), é o principal elemento organizador do pensamento de Ignácio Rangel. Ela resulta de uma adaptação do materialismo histórico marxista ao caso específico da economia brasileira, porém, ao invés de uma sucessão de modos de produção, subdividiu o conceito marxista de "relações de produção" em relações internas e relações externas 6 . Por seu turno, cada uma dessas relações teria também um lado interno e outro externo. Quando são preenchidas as condições para a passagem a um estágio superior — quando as

\footnotetext{
${ }^{4}$ Em crônica já citada, Rangel desabafou: "Nada me obriga a escolher líder algum, porque, afinal, não sou apenas um cidadão, mas também um economista. Um economista de esquerda (grifo do autor) [...] que continuou, infatigavelmente, a trabalhar seus esquemas, contra o vento e a maré, mas que tem a consciência de estar vencendo. Que viu chegar o momento de ver suas ideias - aquelas pelas quais se bateu, solitariamente, por tantos anos, expondo-se à chacota dos doutores - serem postas em circulação, sem referência ao seu nome". Ibid em, nota 2, p. 155. Numa possível identificação aos "doutores" a que Rangel se referia, Bresser-Pereira (1993) lembra-se de um seminário na USP organizado por Delfim Netto, em 1964, do qual participou, em que as teses de Rangel sobre inflação foram criticadas. Paradoxalmente, ao assumir o Ministério da Fazenda, em 1967, Delfim colocou em prática uma política econômica consistente com a tese de Rangel de que a inflação brasileira, na época, era fundamentalmente de custos.

${ }^{5}$ O modelo do "ciclo real de negócios" (Sachs-Larrain, 2000) — baseado na tese de Joseph Schumpeter de que o capitalismo é caracterizado por ondas de "destruição criadora", provocadas por choques aleatórios de tecnologia - teve grande influência no pensamento de Rangel, como se pode concluir da famosa frase de Schumpeter de que "os ciclos não são, como as amígdalas, coisas que podem ser separáveis do corpo [...]”, citada por Rangel (1985a).

${ }^{6}$ Segundo Bresser-Pereira (1993, p. 102): “O método utilizado por Rangel para analisar a economia brasileira sempre foi essencialmente histórico. Sua origem marxista é evidente. Mas Rangel usa Marx com absoluta liberdade [...] Rangel não se deixa levar por uma postura ideológica romântica em relação à burguesia, não aplica o método mecanicamente através de simples transposição das fases históricas ocorridas na Europa que Marx estudou, não se esquece jamais das especificidades brasileiras”.
} 
forças produtivas da sociedade crescem, entrando em conflito com as relações de produção existentes - surge uma "nova dualidade", porém apenas um dos seus lados muda, permanecendo o outro com a mesma estrutura. Esta é a " $1^{a}$ lei da dualidade brasileira" ${ }^{7}$.

Posteriormente, Rangel incorporou o conceito de ciclo longo à tese da dualidade. Nesse sentido, resgatou a teoria dos ciclos longos do economista russo Nikolai Kondratieff ${ }^{8}$, desenvolvida por volta dos anos 1920. Os ciclos de Kondratieff tem duração aproximada de meio século, dividido em um quarto de século na fase "a", ou ascendente, e outro quarto na fase "b" ou descendente. O Brasil se insere nos ciclos longos da economia mundial da seguinte forma: na fase ascendente, é favorecido pelo aumento de suas exportações; na fase descendente (crise), devido à escassez de divisas, se dedica a substituir importações. As fases "a" do ciclo de Kondratieff foram 1790-1815, 1847-1873 e 1896-1920, enquanto as fases "b" compreenderam os períodos 1815-1847, 1873-1896 e 1920-1948. Rangel inclui um $4^{\circ}$ ciclo de Kondratieff, sendo 1948-1973 a fase "a" e após 1973 (1 choque do petróleo) teria começado a fase " $\mathrm{b}$ " ${ }^{9}$.

O que diferencia o caso brasileiro das demais formações históricas clássicas, segundo Ignácio Rangel, é que existe uma interação entre o desenvolvimento das forças produtivas e das relações de produção internas e externas e, por causa da sua dependência em relação às economias centrais, estas últimas são determinantes em última instância do desenvolvimento das primeiras. Para explicar o desenvolvimento econômico, Rangel divide a economia brasileira em três setores: o primeiro, e mais atrasado, formado pela agricultura feudal ou pré-capitalista (ou de subsistência); o segundo, pela economia de mercado capitalista (todas as demais atividades) e, o terceiro, pelo comércio exterior. A transformação da economia seria sempre resultado da ação que o segundo setor (o capitalista) exerce sobre o primeiro, a partir de estímulos oriundos do terceiro setor.

A contrapartida política da tese da dualidade estaria na base da formação do Estado brasileiro. A mudança de um modo de produção para outro está associado a um "pacto de poder" que resulta da aliança de apenas duas classes dirigentes, uma representando o segmento interno e outra o segmento externo. A transição, de uma dualidade para outra, se faz por cooptação, isto é, "pela exclusão, pelo próprio grupo dirigente, dos elementos mais arcaicos, e sua substituição por outros, representa-

\footnotetext{
${ }^{7}$ Cf. Rangel (1981, p. 12).

${ }^{8}$ Segundo Rangel (1982, p. 17), "Kondratieff tornou-se um profeta maldito dos dois lados da Cortina de Ferro". Na ex-União Soviética, foi destituído de seus cargos, preso e deportado para a Sibéria. No Ocidente, se não fosse Schumpeter, que usou o seu nome para denominar os ciclos longos, teria sido um ilustre desconhecido. Rangel atribui esse descaso ao fato de que a sua teoria era desfavorável tanto ao capitalismo, por prever que, de tempos em tempos, a prosperidade acabaria (entraria na fase "b"); quanto ao socialismo, por admitir que, após cada crise, o capitalismo não se enfraqueceria - como previra Lênin - mas se fortaleceria (entraria novamente na fase "a").

${ }^{9}$ Ver, a esse respeito, o texto "O Brasil na fase "b" do $4^{\circ}$ Kondratieff" incluído na coletânea Ciclo, tecnologia e crescimento (Rangel, 1982).
} 
tivos das novas forças sociais em ascensão" ${ }^{10}$. A história das dualidades brasileiras, segundo a cronologia de Ignácio Rangel, é mostrada nos diagramas a seguir ${ }^{11}$.

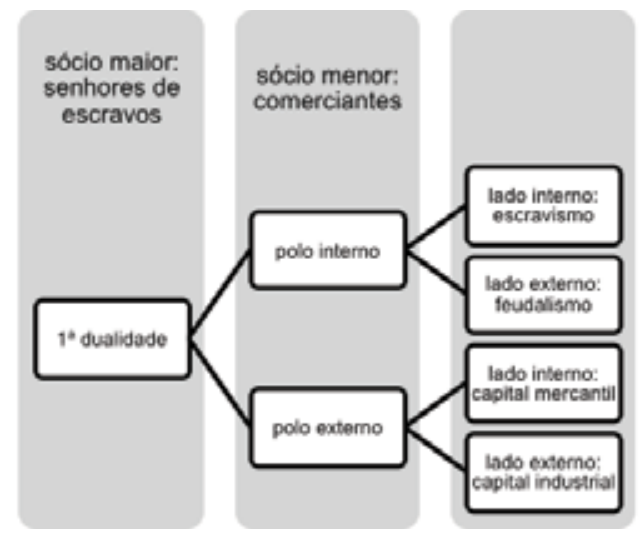

A primeira dualidade brasileira, assim como as que vieram depois, formou-se na fase "b" do ciclo longo do $1^{\circ}$ Kondratieff. O polo externo definiu-se com a substituição do capital mercantil português pelo nascente capitalismo mercantil brasileiro. Surgia nesse momento a classe dos comerciantes (principalmente exportadores-importadores), que seria uma das classes dirigentes do Estado no papel de sócio menor. Esses comerciantes, predominantemente estrangeiros, ainda estavam politicamente despreparados para o exercício do poder, mas eram uma espécie de "correia de transmissão" através da qual o capital industrial do centro dinâmico impulsionava todo o sistema de acordo com os seus interesses.

No polo interno, a sociedade estruturava-se em torno da fazenda de escravos. Emergia dela o sócio maior da primeira dualidade, ou seja, a classe dos barões senhores de escravos. Dois acontecimentos — a independência (1822) e a abdicação de Dom Pedro I (1831) — são marcos históricos das mudanças efetivadas. No lado externo, havia toda uma pressão, sobretudo da Inglaterra, para que o escravismo fosse substituído pelo latifúndio feudal. No lado interno, o comércio de escravos abastecia regularmente não só a lavoura como também uma relativa diversificação da fazenda de escravos. A mudança do lado interno do polo, segundo Rangel (1981), só poderia acontecer se os escravos fossem incapazes de garantir a autossuficiência, a qual estava ligada tanto ao número de cativos quanto à disponibilidade de terras. Ambas as condições passaram a existir com a proibição do tráfico (1850) e com a lei que garantia que todas as terras devolutas passassem a pertencer aos fazendeiros. Abria-se, portanto, a possibilidade de mudança de dualidade.

\footnotetext{
${ }^{10}$ Rangel (1962) apud Bielschowsky (1996, p. 215).

${ }^{11}$ A análise que segue, assim como a elaboração dos diagramas, está baseada no artigo de Rangel "A história da dualidade brasileira”, publicado na Revista de Economia Politica (vol 1, n. 4, out.-dez./1981).
} 


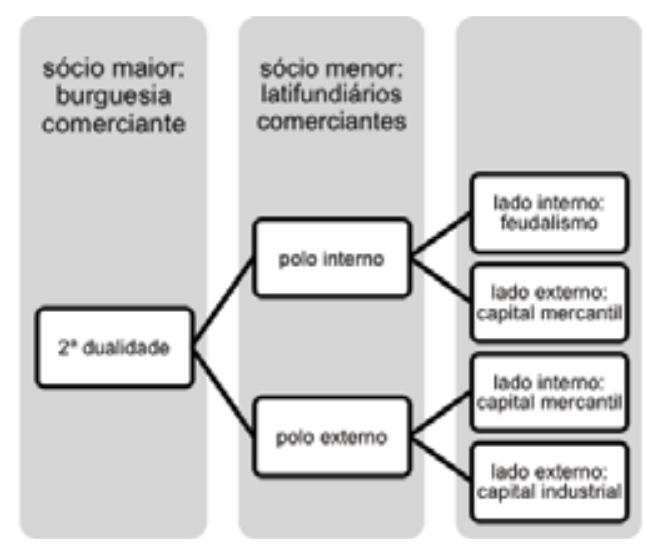

A segunda dualidade brasileira tem lugar na fase recessiva do $2^{\circ}$ Kondratieff, datada do início dos anos 1870. Nela, o escravo passa a exercer um papel análogo ao do "servo da gleba" do feudalismo europeu. $\mathrm{Na}$ medida em que o servo está interessado no resultado do seu trabalho, passa a ter uma produtividade muito maior do que a do escravo. A fazenda tende a tornar-se internamente feudal e externamente uma empresa comercial. Paralelamente, o senhor de escravos se convertia em "senhor feudal" no lado interno do polo interno e "vassalo" do comerciante no polo externo. Havia agora, portanto, um elemento comum nos dois polos da dualidade: o capitalismo mercantil.

A classe dos comerciantes, nascida nos primórdios do século XIX - em unidade com a burguesia industrial que fazia parte do lado externo do polo externo - encontrava-se agora suficientemente madura para influenciar politicamente os negócios do Estado. Havendo a segunda dualidade nascida na fase recessiva do ciclo longo, esta deveria promover alguma forma de substituição de importações. Caberia ao capital mercantil promovê-la, basicamente incentivando a industrialização interna através de processos artesanais e manufatureiros. Costuma-se datar a última década desse século como a do nascimento da indústria brasileira. A proclamação da República (1889) representou a homologação das mudanças ocorridas na segunda dualidade.

Ao iniciar-se a fase "a" do $3^{\circ}$ ciclo longo, na segunda metade do século XIX e que se prolonga até a I Guerra Mundial (1914-1918), a produção de café no Brasil cresceria em progressão geométrica ${ }^{12}$. Após o final da guerra, ocorre a passagem para a fase " $b$ " do $3^{\circ}$ Kondratieff, que seria marcada por dois acontecimentos de grande repercussão mundial: A Grande Depressão (1929) e a II Guerra Mundial (1939-1945). A terceira dualidade brasileira, portanto, seria inaugurada justamente numa ocasião em que a produção de café se encontrava no auge e que a deman-

\footnotetext{
12 "A produção brasileira, que havia aumentado de 3,7 milhões de sacas (de $60 \mathrm{~kg}$ ) em 1880-81 para 5,5 em 1890-91, alcançaria em 1901-02 16,3 milhões” (Furtado, 1985, p. 177).
} 


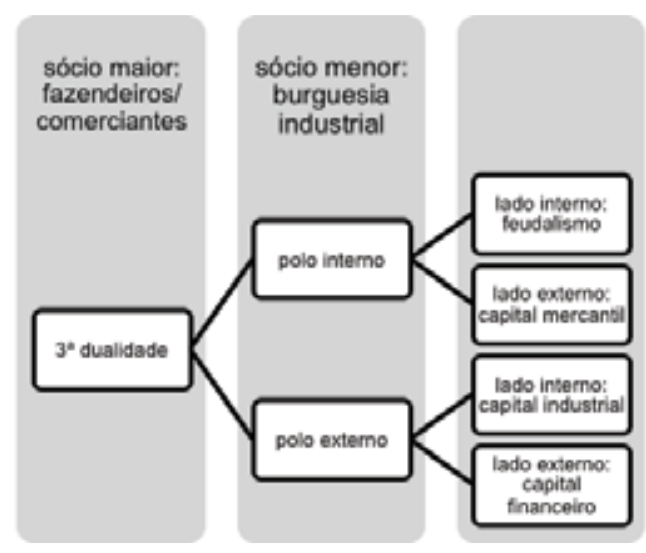

da externa tendia a se retrair ${ }^{13}$. A principal mudança foi passagem do capital industrial para o lado interno do polo externo da dualidade em substituição ao capital mercantil. Sua exclusão do lado externo do polo externo, por sua vez, possibilitaria que outra formação (superior, porque o capitalismo hegemônico está sempre mais avançado) ocupasse o seu espaço, neste caso a do capital financeiro ${ }^{14}$.

Embora como sócio menor da terceira dualidade, a burguesia industrial surgida como dissidência da classe dos comerciantes teria papel fundamental para alavancar o processo de substituição de importações. Como estudado por vários autores ${ }^{15}$, o esgotamento das reservas cambiais e a escassez de divisas criaram, automaticamente, uma reserva de mercado para a produção nacional substitutiva de importações. Segundo Conceição Tavares (1974), quando se inicia a Grande Depressão, o Brasil dispunha de um mercado interno relativamente amplo e uma estrutura industrial que, embora incipiente, possuía uma relativa diversificação. Isso possibilitou a gradativa substituição de importações de bens não duráveis ou simples para bens duráveis ou complexos. Mais adiante, no pós-guerra (ao iniciar-se a fase "a" do $4^{\circ}$ Kondratieff) esse esforço de substituição de importações, com o apoio decisivo de recursos do Estado, alcançaria os bens de capital.

O processo de substituição de importações não só não é interrompido na terceira dualidade como, a partir dela, a economia brasileira passaria a produzir o seu

\footnotetext{
13 “A produção de café, em razão dos estímulos oficiais recebidos cresceu fortemente [...] Entre 1925 e 1929 tal crescimento foi quase cem por cento [...] Enquanto aumenta dessa forma a produção, mantêmse praticamente estabilizadas as exportações. Em 1927-29 as exportações apenas conseguiam absorver duas terças partes da quantidade produzida". Ibidem, p. 181.

${ }^{14} \mathrm{O}$ capital financeiro a que Rangel se refere na terceira dualidade é no sentido atribuído por Hilferding, ou seja, surgido da união do capital industrial com o capital bancário, com a dominância do primeiro sobre o segundo. Não é como ocorre hoje em dia, onde os papéis se encontram invertidos.

${ }^{15}$ Sobre o processo de substituição de importações, ver: Conceição Tavares (1974), Furtado (1985) e Cardoso de Mello (1982), entre outros.
} 
próprio ciclo endógeno ${ }^{16}$. Não se tratava do ciclo longo, causado pela gestação e propagação de novas tecnologias, que é, por sua própria natureza, prerrogativa dos países industrializados integrados ao centro dinâmico. Tais ciclos seriam inerentes à construção do capitalismo industrial e seriam semelhantes aos chamados ciclos médios ou ciclos de Juglar, com duração aproximada de uma década. Após uma fase ascendente, a economia entra em crise, a qual induz algumas mudanças institucionais, em especial no mercado financeiro, estimulando novos investimentos em segmentos econômicos não modernizados. Os efeitos dessa "onda de investimentos" tendem a se propagar por todo o sistema econômico, o qual entra novamente numa fase ascendente.

Como a economia brasileira mergulha numa nova fase descendente? Isso se dá através de um processo que Rangel chamou de "dialética da capacidade ociosa" ${ }^{17}$. Após certo tempo, as atividades que receberam investimentos geram capacidade ociosa enquanto outras atividades persistem como pontos de estrangulamento. $\mathrm{O}$ "choque dos contrários" entre esses dois polos do sistema econômico - um carregado de ociosidade e outro de antiociosidade - engendrará tensões sociopolíticas que, por sua vez, promoverão novas mudanças institucionais que irão desencadear novos investimentos, os quais deslocarão a economia novamente para uma fase ascendente. A teoria do ciclo endógeno de Rangel procurou demonstrar que, ao contrário do que muitos supunham, o modelo de substituição de importações não tinha se esgotado.

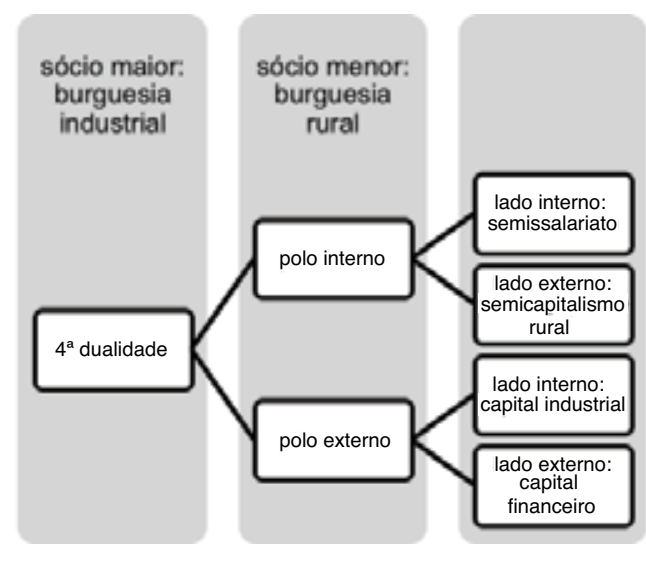

\footnotetext{
16 "Outra singularidade da terceira dualidade está no fato de que, embora havendo começado nas condições da fase recessiva do ciclo longo, a industrialização substitutiva de importações [...] não se interrompeu com a passagem ascendente do $4^{\circ}$ Kondratieff. O dinamismo do processo de industrialização, engendrando demandas de importações sempre novas, fez com que o impulso se mantivesse" (Rangel, 1981, p. 30).

17 “[...] uma vez cumprido o programa de substituição de importações [...] descobríamos que a insuficiência da capacidade para importar ressurgia sob a forma de demanda insatisfeita de um grupo novo de produtos [grifo do autor]. Este é o núcleo do problema que proponho que se estude sob a rubrica de dialética da capacidade ociosa, manifestada pela circunstância fundamental de que, no próprio ato de implantar-se, engendrava o seu contrário, tendendo, portanto, a perpetuar o esforço de desenvolvimento" (Rangel, 1980, p. 132-3).
} 
A quarta dualidade brasileira, que seria também a última, ainda não havia se completado à época em que Rangel estudava o fenômeno. O ano de 1973 ( $1^{\circ}$ choque do petróleo), segundo ele, marcaria a entrada dos países do centro capitalista hegemônico na fase " $b$ " do $4^{\circ}$ ciclo de Kondratieff. No Brasil, a fase descendente do ciclo longo coincidiria com a fase " $b$ " do seu ciclo médio endógeno, pondo termo no chamado "Milagre Econômico" (1968-1973). A partir daí o esforço do II PND (governo Geisel) de manter o crescimento "em marcha forçada" ${ }^{18}$ de forma a completar a substituição de importações no Departamento I da economia (produção de bens de capital) e insumos importados (principalmente petróleo) desembocaria numa grave crise do balanço de pagamentos, a partir do início dos anos 1980 do século passado.

Diante da incapacidade de continuar financiando o crescimento da economia com capital externo, esse financiamento deveria ser feito com poupança interna. Nessa fase, diante do avanço de sua industrialização, o Brasil estaria deixando de produzir muitas coisas importadas simplesmente pela falta de um setor de intermediação financeira capaz de financiar a acumulação de capital. $\mathrm{O}$ "Milagre Econômico" havia levado a algumas atividades econômicas a crescerem além dos limites impostos pelo mercado, gerando, portanto, sobreacumulação de capital. Era preciso fazer com que essas atividades detentoras de poupança, mas impossibilitadas de investir em suas próprias instalações, fossem estimuladas a transferir recursos para outras atividades carregadas de antiociosidade, que Rangel identificou nos serviços públicos. Sua sugestão, na época, foi a criação de uma nova lei de concessão de serviços públicos, que permitisse ao setor privado encarregar-se, de forma crescente, pelos investimentos públicos de infraestrutura.

A burguesia industrial, finalmente, se tornaria o sócio maior na quarta dualidade, representando o polo externo, e tendo como sócio menor a nova burguesia rural, representando o polo interno. Para viabilizar a mudança no polo interno da dualidade, seria preciso eliminar os últimos resquícios do latifúndio feudal — condição necessária para criar empregos no meio rural. Nesse sentido, Rangel advoga a diminuição do preço da terra. $\mathrm{Na}$ sua visão, o preço da terra no Brasil não decorre do seu uso enquanto tal, mas da sua utilização como especulação financeira. A estagnação econômica seguida de inflação (na fase descendente do ciclo endógeno) desencadeia um processo de valorização dos ativos reais, como a terra, que nada tem a ver com o seu valor territorial. Nesse caso, os títulos fundiários concorrem com os títulos mobiliários ${ }^{19}$.

Tendo discordado da esquerda, nos anos 1950, do papel prioritário da reforma

\footnotetext{
${ }^{18}$ A expressão “marcha forçada” como característica do período 1974-1979 se deve a Castro (1985).

19 “[...] o mesmo processo recessivo, que se faz acompanhar de exacerbação do processo inflacionário, também desencadeia um processo de 'valorização' da terra, no sentido de elevação dos preços desse fator, em óbvio descompasso com a renda territorial (grifo do autor). Por outras palavras, os títulos fundiários comportam-se em contracorrente com os mobiliários. A mesma recessão que deprime os valores mobiliários impele para cima os títulos fundiários” (Rangel, 1982a, p. 67).
} 
agrária para desenvolver o Brasil — dado que o processo de substituição de importações criava uma reserva de mercado para a indústria - a partir da quarta dualidade, a reforma agrária tornava-se imperativa ${ }^{20}$.

\section{INFLAÇÃO: NEM MONETARISTA, NEM ESTRUTURALISTA}

Embora a teoria quantitativa da moeda tenha origens remotas ${ }^{21}$, os seus princípios básicos foram elaborados, no final do século XIX e início do século XX, por Wicksel (na Suécia), que relacionou a inflação com a taxa de juros, Marshall (na Inglaterra), que explicou a inflação pelo princípio da oferta e procura, e Fisher (nos Estados Unidos), cuja contribuição passou a ser um "divisor de águas" para todos os demais autores monetaristas que se seguiram, sendo Milton Friedman o mais importante deles.

A equação de trocas, de Fisher, é dada por $\mathrm{MV}=\mathrm{PT}$, onde $\mathrm{M}$ representa a quantidade de moeda, $\mathrm{V}$ é a velocidade de circulação da moeda, $\mathrm{P}$ é o nível geral de preços e $\mathrm{T}$ é o total de transações realizadas na economia em certo período (produto). Pela hipótese clássica de pleno emprego, o produto não se altera, de modo que $\mathrm{T}$ pode ser considerado estável no curto prazo. Levando em conta que as condições institucionais que determinam o número de vezes que a moeda troca de mãos mudam muito lentamente ao longo do tempo, então $V$ também pode ser considerado como uma constante no curto prazo. Nessas condições, é a quantidade de moeda $\mathrm{M}$ - que representa a demanda — é responsável pela alteração no nível geral de preços $P$.

Já a análise estruturalista da inflação surgiu dentro do referencial teórico desenvolvido pela CEPAL ${ }^{22}$, cujas teses principais foram resumidas por Sunkel (1962) através de um esquema geral para a análise da inflação. Esse esquema, idealizado com base na economia chilena, se propunha a identificar as pressões inflacionárias e os seus mecanismos de propagação. As pressões inflacionárias básicas refletiam

\footnotetext{
20 "Há tempos que o problema da terra, no Brasil, tomou a forma de um problema financeiro [grifo do autor]. Assim, a configuração gradativa do novel capitalismo financeiro trará em seu bojo uma reforma agrária, nada menos. Noutros termos, a reforma agrária que não precedeu a industrialização, como julgávamos nós, os revolucionários dos anos [19]30, terá de vir agora, como coroamento da mesma industrialização" (Rangel, 1985, p. 21).

${ }^{21}$ Já no final do século XVI, os escritos mercantilistas faziam relação da inflação com as reservas de ouro de um país e seu balanço de pagamentos. Entre os chamados filósofos políticos de meados do século XVIII, críticos dos mercantilistas e precursores dos economistas clássicos, a correlação entre moeda e preços era ainda mais visível (em especial, em David Hume).

${ }^{22}$ Comissão Econômica para a América Latina e o Caribe, órgão ligado às Nações Unidas, sediado em Santiago do Chile. Fundada em 1948, tendo à frente o economista argentino Raúl Prebisch, seu objetivo principal era desenvolver um marco teórico alternativo (Desenvolvimentismo) para a América Latina, até então dominado por teorias construídas com base no cenário das nações que detinham a hegemonia econômica.
} 
a incapacidade dos setores produtivos de atender ao crescimento da demanda, em especial a agricultura devido à inelasticidade da oferta de alimentos.

A palavra “ilusão", usada por Rangel (1978) para caracterizar tanto a visão monetarista quanto a estruturalista, dá bem uma ideia do quanto não acreditava no poder de explicação dessas escolas para explicar a inflação brasileira nos anos 1960. Um ano antes de publicar o seu clássico A inflação brasileira, escreveu um artigo com esse mesmo título em que ironizava a ortodoxia, seja de direita, seja de esquerda ${ }^{23}$. Nossos ortodoxos monetaristas (de direita), dizia ele, não percebem que a moeda é passiva, ou seja, é o aumento de preços que leva as autoridades monetárias a aumentarem a quantidade de moeda e não o contrário. Nossos ortodoxos estruturalistas (de esquerda), por outro lado, "tomaram a nuvem por Juno" ao não perceberem que é a estrutura concentrada de intermediação que, ao não repassar os aumentos de preços obtidos ao nível do consumidor final para o produtor, desestimula o aumento da produção por parte deste último e não uma suposta inelasticidade da oferta agrícola (Rangel, 1978, p. 29).

Ao convergirem para a tese das "inelasticidades da oferta" — os monetaristas com base na hipótese do pleno emprego clássica; os estruturalistas identificando "ponto de estrangulamento" na agricultura - ambas as correntes concluíram, equivocadamente, tratar-se de inflação causada por excesso de demanda quando, ao contrário, existia insuficiência de demanda ${ }^{24}$. O que os representantes dessas correntes não perceberam é a existência de capacidade ociosa e, mais ainda, "que a inflação cresce com a capacidade ociosa, quando devera regredir” (Rangel, 1978, p. 15). O que ocorre é que a inflação se expande a "demanda nominal”, mas não altera a "demanda a preços constantes, a qual consequentemente, não é nem maior, nem menor, do que antes" (Rangel, 1962, p. 269). Se a demanda real se alterasse, conduziria a uma expansão da renda e não a uma elevação dos preços, conclui Rangel.

Por que, para Ignácio Rangel, o monetarismo não passa de uma "ilusão"? Para chegar lá, retornemos à equação de trocas de Fisher. Invertendo o significado da equação, suponha que a variação no volume de moeda seja determinada pela elevação dos preços. Nessa hipótese, a igualdade da equação de Fisher MV = PT se converte na desigualdade $\mathrm{MV}<P_{1} \mathrm{~T}$. Essa hipótese não foi considerada pelos monetaristas porque, como se trata de uma "equação de trocas", para reestabelecer a igualdade entre o lado direito e esquerdo da equação, uma parte da produção não entraria no mercado, tal que $\mathrm{MV}=P_{1}(\mathrm{~T}-\mathrm{t})$, onde $\mathrm{t}$ é a parte do produto físico re-

\footnotetext{
23 “[...] Cumpre notar que essa ortodoxia verdadeira não é privilégio nem de esquerda, nem da direita, sendo, ao contrário, um fundo comum da ciência econômica, pois as equações de Fisher já estavam perfeitamente formuladas nos parágrafos de Marx, e não há, no mundo moderno, nenhuma ortodoxia mais verdadeiramente ortodoxa do que a dos economistas soviéticos" (Rangel, 1962, p. 267). Dizer isso hoje é fácil, mas não naquela época em que o conflito ideológico entre esquerda e direita era muito acirrado.

24 "Porque a verdade é que o Brasil é um país de baixíssima propensão a consumir - e nem se pode conceber que seja de outro modo, dado o atual esquema de (má) distribuição de sua renda" (Rangel, 1978, p. 35).
} 
tirada do mercado. Em concorrência pura, como supõem os monetaristas, isso não poderia acontecer. Mas numa economia de características monopolistas como a brasileira, a hipótese de retenção voluntária da oferta ou de capacidade ociosa planejada passa a ser perfeitamente plausível.

Essa retenção de parte da produção pelas empresas, caso persista por muito tempo, resultaria em queda da renda real pelo aumento do nível dos estoques. Se isso não ocorre é porque a elevação dos preços (de $\mathrm{P}$ para $\left.P_{1}\right)$ para provoca alteração no primeiro membro do lado esquerdo da equação de trocas (de $\mathrm{M}$ para $M_{1}$ ), que poderia ser reescrita como $M_{1} \mathrm{~V}=P_{1} \mathrm{~T}$. Em outras palavras, a retirada de parte do produto do mercado $(\mathrm{t})$, alterando o total de bens e serviços oferecidos ao mercado para T- t, sustenta o acréscimo no preço $P_{1}$. A emissão de moeda passa a ser, portanto, consequência ao invés de causa da inflação. O aumento do meio circulante pelo governo, de $\mathrm{M}$ para $M_{1}$ destina-se a suprir as necessidades de caixa das empresas devido ao alto custo de manutenção de estoques, reestabelecendo o equilíbrio da equação de trocas a um nível maior de inflação. O papel do governo nesse processo, portanto, é passivo ${ }^{25}$.

O problema fundamental, para Ignácio Rangel, é descobrir por que algumas empresas privadas que dominam o mercado, em certos períodos, decidem elevar os seus preços - e mais - por que preferem até mesmo não levar uma parte do produto ao mercado ao invés de baixarem os preços? Ora, à medida que nos afastamos do regime de concorrência pura e adotamos a tese mais realista da concentração de mercado, a manutenção da margem de lucro (regra do mark-up), em períodos de escassez da demanda, passa a ser uma explicação convincente.

Nesse ponto, a teoria de formação de preços de Ignácio Rangel em muito se assemelha a de Michal Kalecki, embora não seja certo que ele conhecesse a obra do economista polonês ${ }^{26}$ à época (início dos anos 1960). Mesmo não conhecendo Kalecki, a afinidade provavelmente se deu porque ambos tiveram o mesmo ponto de partida (Marx). Para Kalecki, a característica normal da economia é operar com capacidade ociosa devido ao grau de monopolização das economias capitalistas ${ }^{27}$. O preço do produto $(p)$ é determinado por uma margem (mark-up) sobre os custos diretos $(u)$, calculado pela equação $p=m u+n p^{*}$, sendo $m$ e $n$ coeficientes posi-

\footnotetext{
25 “Tudo se passa, portanto, como se a sociedade civil, movida por maquiavélica malícia, preparasse uma armadilha para o Estado. Este será premiado se desempenhar o seu papel na tragicomédia da inflação; e será punido se recusar a fazê-lo" (Rangel, 1978, p. 26).

${ }^{26}$ A primeira edição de A inflação brasileira é de 1963, quando a obra do economista polonês era pouco conhecida no Brasil. Por esse motivo, no prefácio da $3^{a}$ edição (1978), Luiz Carlos Bresser-Pereira não acredita que Ignácio Rangel estivesse familiarizado com a teoria kaleckiana. O próprio Rangel, no posfácio que escreveu para a edição de 1978, mostrou estar em dúvida a esse respeito. “[...] tanto podia dizer que sim, como que não" (Rangel, 1978, p. 129).

${ }^{27}$ Não é outro o pensamento de Rangel, como pode ser comprovado pela leitura do prefácio do livro Recursos ociosos e política econômica (1980, p. xi): “[...] o progresso não depende, necessariamente, da expansão das forças produtivas, dado que, normalmente (grifo do autor), a sociedade subutiliza as forças de que dispõe. Assim, quando o marxismo me ensinou que toda crise é crise de superprodução, disse-me uma antiga novidade".
} 
tivos que representam a política de fixação de preços da firma e $p^{*}$ o preço dos demais concorrentes naquele mercado. O poder de mercado da empresa reflete o seu grau de monopólio, dado pela razão $\frac{p}{\mathcal{u}}$. Quanto menor o poder de mercado da empresa, mais próximo de $p^{*}$ deverá situar-se seu preço e vice-versa ${ }^{28}$.

Conquanto a escola estruturalista tenha entendido, corretamente, a inflação como um fenômeno endógeno, também, para Ignácio Rangel, produziu outra "ilusão". Ao associar o aumento dos preços com os "gargalos" da estrutura da economia, notadamente a inelasticidade da oferta agrícola, os estruturalistas inverteram a ordem natural das coisas: a inelasticidade está na demanda e não na oferta. É o intermediário oligopsonista-oligopolista que impede que a elevação dos preços pagos pelo consumidor seja transferida para o produtor. Como a elevação de preços deprime o salário real do trabalhador — dado o peso da alimentação no orçamento das classes de renda mais baixas - o que existe é uma crônica inelasticidade da demanda e não da oferta.

A parte mais surpreendente do raciocínio de Rangel ainda não foi desvendada. A redução da demanda não ocorre nos chamados bens-salário e sim em outros bens, cuja procura é mais elástica do que os alimentos, tais como vestuário, calçados, etc. Em outras palavras, o aumento da parcela da renda do trabalhador comprometida com a alimentação provoca um efeito substituição na estrutura de consumo popular, aumentando o peso dos alimentos em detrimento de outras mercadorias e serviços menos essenciais. O aumento dos estoques, portanto, não se verifica no segmento de empresas que aumentaram os preços dos seus produtos e sim nas empresas cuja elasticidade preço da demanda é maior. Os preços não caem, como supõem os monetaristas, porque a elevação inicial de preços e a retenção de estoques têm lugar em setores diferentes do mercado e são estas últimas empresas que recorrem ao sistema bancário à procura de crédito para manter os estoques que forçam o governo a emitir, sancionando a inflação.

Desfeitas as "ilusões" monetarista e estruturalista, Ignácio Rangel passa a expor o seu próprio pensamento a respeito das causas do processo inflacionário brasileiro da primeira metade dos anos 1960. Suas referências teóricas são Keynes e Marx. Do primeiro, foi buscar o conceito de "propensão marginal a consumir" para explicar a proporção da renda que é gasta com bens de consumo. Do segundo, se apropriou do conceito de "taxa de exploração" - proporção do excedente ou mais-valia realizada sobre os salários pagos pelo trabalho - para entender o processo de concentração de renda no país. Juntando os dois conceitos, Rangel concluiu que pelo fato da taxa de exploração ser alta é que a propensão marginal a consumir é baixa.

Um passo mais adiante e Rangel consegue explicar a recorrência de crises econômicas ou, como costumava chamar, as fases descendentes dos ciclos econômicos. Na medida em que é apropriada uma fatia maior da mais-valia (ou que aumenta a taxa de exploração), as condições para aumento do investimento tendem

${ }^{28}$ Ver Kalecki (1983, p. 8). 
a se deprimir por causa da insuficiência de demanda efetiva. Esta queda, por sua vez, resulta do aumento de produtividade não repassada para os salários. O dilema da economia brasileira reside, para Rangel, entre escolher entre crescimento cada vez mais acelerado - de forma a ocupar a grande carga de capacidade ociosa acumulada em seu parque industrial - e a crise econômica.

Finalmente, Rangel conclui que a inflação é uma espécie de mecanismo de sustentação do nível de crescimento da economia. Para que a economia cresça é preciso manter um nível mínimo de demanda, o que só é possível devido à existência da inflação. A elevação de preços tem como contrapartida a desvalorização da moeda e, com isso, provoca uma "corrida aos bens materiais", promovendo uma elevação forçada dos investimentos pelas empresas e das compras de bens duráveis pelas famílias de renda média e alta. A inflação, portanto, está relacionada com aquilo que mais estratégico existe para uma economia, ou seja, a sua própria taxa de formação de capital ${ }^{29}$.

\section{“MILAGRE” E “ANTIMILAGRE”}

O "Milagre Econômico" (1968-1973) ficou marcado como um período de alto crescimento da economia brasileira, sobretudo entre 1970 e $1973^{30}$. Para Rangel (1985a), entretanto, esse período nada teve de "milagroso". Foi simplesmente uma decorrência de uma conjuntura extremamente favorável, marcada pela coincidência da fase "a" do seu ciclo endógeno com a etapa final da mesma fase do $4^{\circ}$ Ciclo Longo (ou de Kontradieff). Não sendo apenas uma economia reflexa, a partir do início deste Ciclo Longo, haveria fatores internos que seriam coadjuvantes do processo de recuperação da economia brasileira. Dentre estes, Rangel destaca a implantação da correção monetária (curiosamente, a "indexação" seria eleita como causa da hiperinflação dos anos 1980). Porém, assim como a Instrução 70, de Eugênio Gudin, teve muito a ver com a fase de crescimento do governo JK; a correção monetária, de Octávio Bulhões, foi responsável pelo "Milagre" de Delfim Netto. A partir de 1973, quando a economia capitalista entraria na fase "b" do Ciclo Longo, o Brasil ainda permaneceria na fase ascendente do seu ciclo breve até o final da década, situação que mudaria drasticamente a partir do início dos anos 1980.

Consciente de que o Brasil se encontrava na fase descendente do seu ciclo médio endógeno que, pela primeira vez, coincidia com a fase "b" do ciclo longo exógeno, o interesse de Rangel volta-se para a conjuntura econômica, particular-

\footnotetext{
29 “[...] Vista sob esse ângulo, a inflação se relaciona não com movimentos superficiais da economia, mas com o que há de mais estratégico nela, isto é, com a taxa de capitalização ou de formação de capital” (Rangel, 1978, p. 32).

${ }^{30}$ No seu período de auge (1970-1973), o PIB brasileiro cresceu, em média, acima de $10 \%$ ao ano e a produção industrial cresceu, também em média, 13\% ao ano (Rangel, 1985a).
} 
mente na busca de saída para a estagflação que assolou o país na década de $1980^{31}$. Acertadamente, Rangel previu que a recuperação de 1984 não representava uma passagem para a fase ascendente do ciclo endógeno e sim um efeito induzido de uma temporária recuperação mundial relacionada com o déficit do Tesouro norte-americano. $\mathrm{O}$ financiamento do déficit, a juros elevados, se constituía num verdadeiro "aspirador" de recursos do resto do mundo, praticamente inviabilizando aos países dependentes altamente endividados - como o Brasil - de financiarem os seus déficits de Balanço de Pagamentos. Nesse sentido, a economia brasileira, que contava com considerável reserva de capacidade ociosa herdada do ciclo anterior, viu-se forçada a buscar divisas através de superávits na sua balança comercial para contrabalançar a falta de financiamento externo. Portanto, 1984 foi apenas um suspiro de recuperação que não duraria muito.

A década de 1980 marcou também o início do processo de aumento dos preços que culminou com hiperinflação. Rangel discordava da tendência dominante entre os economistas de que a inflação era causada por "excesso de demanda" e via a inflação com um componente da "síndrome da recessão" ${ }^{32}$. Somente se poderia falar em "aquecimento" da demanda na fase ascendente do ciclo, mas não na fase descendente, quando a demanda é mínima. Ora, na recessão, a tendência é haver subutilização da capacidade instalada, de modo que a redução da oferta é, até certo ponto, planejada. Contudo, o que leva o empresário a operar com capacidade ociosa e gerar aumento dos preços? Ocorre que, numa economia oligopolizada como a brasileira, quando a capacidade instalada ultrapassa a demanda, as empresas, defensivamente, reduzem a oferta e aumentam os preços para manter a sua margem de lucro. Essa é a explicação.

Quando Rangel diz que a inflação faz parte da "síndrome da recessão" ele quer dizer que não há como baixar a inflação sem atacar a causa da recessão. Nesse ponto, entra em cena a "dialética da capacidade ociosa". Na recessão (ou fase "b" do ciclo endógeno), existe um "polo de ociosidade", composto de atividades que estiveram se modernizando prioritariamente na fase ascendente do ciclo, e um "polo de antiociosidade", do qual fazem parte atividades atrasadas tecnologicamente e cujo desenvolvimento passa a ser exigido pela sistema para sair da recessão. $\mathrm{O}$ nó a ser desatado consiste em criar condições para investimento de recursos das empresas daquelas atividades carregadas de ociosidade para os setores retardatários. Que setores seriam esses? Os grandes serviços de utilidade pública, como transportes pesados de carga, transportes de massa de passageiros (metrôs), energia, serviços urbanos, etc. Admitindo que, na época, o setor de intermediação financeira ainda

\footnotetext{
${ }^{31}$ Ver, especialmente, o artigo "Recessão, inflação e dívida interna", publicado no segundo semestre de 1985, na Revista de Economia Política (vol. 5, n. 3, jul.-set./1985).

32 “Trata-se, em suma, de precisar a síndrome da recessão. Os sintomas isolados que compõem essa síndrome já se encontram razoavelmente cobertos, mas cada especialista tende a privilegiar o aspecto que, per faz et nefaz, obteve a sua atenção, perdendo de vista a floresta, por causa das árvores” (Rangel, 1982a, p. 65).
} 
não estava preparado para transferir poupança de um setor para outro, a solução do problema teria de passar pela intervenção do Estado.

O problema, segundo Rangel (1985), admite duas soluções: a) a poupança privada seria transferida (via dívida pública) para o Estado que se encarregaria de investir nas atividades retardatárias; b) ao Estado apenas caberia criar condições propícias ao investimento do setor privado nos serviços públicos, mediante mudanças no arcabouço legal. Desde logo, Rangel descarta a primeira alternativa, por se colocar no longo prazo, enquanto o problema exige solução de curto prazo. Para reforçar seu argumento, lembra que, no limiar de nossa industrialização, os atuais serviços públicos nasceram como concessões a empresas privadas, quase sempre estrangeiras ${ }^{33}$. Posteriormente, o Estado promoveu a nacionalização desses serviços. Agora, não deverá ser diferente. Haverá uma redistribuição de responsabilidades entre o setor público e o setor privado, mas a "variável estratégica é a privatização", conclui Rangel ${ }^{34}$.

A retomada do crescimento exigiria, para Rangel, uma reformulação institucional do setor de intermediação financeira, de modo a possibilitar que os lucros dos setores portadores de capacidade ociosa sejam transformados em excedente social a ser reinvestido em projetos capazes de eliminar os "gargalos" da economia. A mudança institucional a que se refere Rangel passaria por uma generalização do uso do "poder de aval" do Estado, mudança na qual o BNDES deveria desempenhar "função-chave" ${ }^{35}$. Mas não basta apenas uma mudança no arcabouço legal; seria preciso fazer com que as taxas reais de juros se transformassem de positivas em negativas - como acontecia à época em que os serviços públicos foram estruturados no Brasil. Aqui a análise de Rangel sofre forte influência de Keynes, na medida em que considera que o investimento só é viável se a eficácia marginal do capital for maior que a taxa de juros de mercado.

Não resta dúvida que o problema dos juros é o mais difícil de ser resolvido, dado que o Brasil, tanto no final do século passado como no presente século, está entre os países que apresentam as mais elevadas taxas de juros reais do planeta. Mas se há algo errado, adverte o mestre, é a existência de taxas reais de juros fortemente positivas e não o fato de, eventualmente, serem negativas. Segundo ele, a eficácia marginal do capital das empresas com capacidade ociosa é negativa e,

\footnotetext{
${ }^{33}$ Um exemplo de que a economia brasileira ainda não estava preparada para o fornecimento de tais serviços é o da empresa estrangeira Light que, para implantar o serviço de bondes nas grandes cidades, teve de importar desde o equipamento pesado para a geração e transporte de energia até os próprios bondes (Rangel, 1985).
34 “A presente crise deverá desembocar numa solução desse segundo tipo. Isso implicará, numa primeira etapa, a progressiva participação do capital privado na implantação de projetos rompedores de pontos de estrangulamento; [...] numa segunda etapa, não é possível excluir a possibilidade, ou de privatização pura e simples da atividade ou, dependendo das circunstâncias, de conversão dos serviços públicos de administração direta, ou das empresas públicas, em serviços públicos concedidos a empresas privadas" (Rangel, 1982c, p. 81).

${ }^{35}$ Ibidem, nota 30, p. 22.
} 
pela lógica, é essa eficácia que deve orientar a taxa de juros. Entre as causas que contribuíram para que a taxa real de juros se tornasse positiva está o fato de que o setor público não tem outra garantia a oferecer a não ser o aval do Tesouro. Ora, o endividamento crescente do Estado e o risco de insolvência deste tornam esse aval de valor discutível, o que explica a existência de taxas reais de juros positiva.

Por uma simples questão de bom-senso se chega à conclusão de que nenhum serviço público será capaz de remunerar a empresa privada com tarifas compatíveis com as elevadas taxas de juros do mercado. Para que as taxas reais de juros sejam menores que a eficácia marginal do capital investido nesses setores, torna-se necessário que o Estado levante recursos, através de sua influência no setor financeiro ou dos bancos públicos, e transfira-os para essas empresas com forte subsídio. Pode parecer que nada terá mudado com a passagem dos serviços públicos da responsabilidade do Estado para a empresa privada. Porém, em troca do seu aval, o Estado deixará de comprometer recursos fiscais futuros e ainda terá como garantia a hipoteca dos bens pertencentes às empresas concessionárias. Em caso de má prestação do serviço público, poderá o Estado executar a hipoteca do concessionário, inclusive tomando-lhe a concessão, se for o caso, e negociando-a com outro concessionário.

Em resumo, será por esta porta que nascerá o "capital financeiro brasileiro", isto é, o casamento entre o capital bancário remodelado e o capital industrial investido nos serviços públicos. Na aparência, nosso capital financeiro estará nascendo como capitalismo de Estado. Mas isso não deve ser confundido com socialismo. Rangel mantém a esperança viva de que o Brasil ainda possa caminhar para o socialismo, mas não pela via da estatização da economia ${ }^{36}$. Trata-se simplesmente de uma "rua de mão dupla": de um lado, o setor privado, não encontrando mercado à altura da capacidade produtiva criada na precedente fase ascendente do ciclo, recorre ao Estado para resolver seu problema; de outro, o Estado, prestes a esgotar a sua capacidade de endividamento, vê uma saída para a falta de recursos na transferência dos serviços públicos para a órbita privada. Em definitivo, conclui Rangel (1982c, p. 80), "resta apenas o fato de que certas atividades, em cada momento, estão a cargo do setor privado, enquanto outras integram o setor público. Não necessariamente as mesmas, com o correr do tempo".

\section{PROFETA OU VISIONÁRIO?}

Ao nos associarmos às comemorações do centenário do nascimento de um dos mais originais pensadores brasileiros, que juízo podemos fazer dele? Profeta ou visionário? Ignácio Rangel era um pouco de cada coisa. Tanto poderia ser visto

\footnotetext{
36 "Seria fútil, ou mal-intencionado, identificar esse estado de coisas com o advento do socialismo. O Brasil, por certo, caminha também para o socialismo, mas não pela via da mera estatização da economia, tanto mais quanto esta, como ficou demonstrado, é uma rua de mão dupla, na qual o capitalismo privado tem ressurgido sempre das próprias cinzas”. Ibidem, nota 31, p. 81 .
} 
como um indivíduo que prediz o futuro, quanto como um sonhador. A simples comparação com o presente, que emerge da leitura das seções precedentes deste texto, revela um Ignácio Rangel profeta. Previu, com cerca de duas décadas de antecedência, a privatização dos serviços públicos ou a concessão de serviços públicos à empresa privada, iniciada durante o governo de Fernando Henrique Cardoso e que chegou, em menor ou maior grau, até o governo Dilma Rousseff. Tinha também sonhos, que alguns podem considerar como utopias, como sua inabalável convicção de que o Brasil caminhava para o socialismo, embora talvez não no sentido comumente associado à palavra. Sua visão de socialismo não era sinônimo de "estatismo", pois acreditava que os ciclos exógenos (das economia centrais) e endógenos (determinados pela "dialética da capacidade ociosa"), mais a escassez de recursos públicos, impunham limites a atuação do Estado no sistema de economia de mercado ${ }^{37}$. Daí haver necessidade da parceria do capital público-privado - sempre com o controle do primeiro -, alternando as suas áreas de atuação ao longo do ciclo econômico, seja para romper com as fases "b" dos ciclos endógenos, seja para galgar mais rapidamente as etapas do desenvolvimento, cujo conceito está baseado no tripé avanço tecnológico/crescimento econômico/justiça social.

Mais importante do que traçar o perfil de I. Rangel, certamente multifacetado, é resgatar a sua contribuição no terreno da economia, de sorte que possa servir de inspiração para as novas gerações de economistas ${ }^{38}$, assim como foi para a geração deste articulista. Formado em Direito, Rangel foi, ao longo de sua vida, um autodidata. Apreendeu economia por conta própria, começando por Marx, até tornar-se um desenvolvimentista, supostamente influenciado pela leitura de Keynes, no único curso formal que frequentou (sobre planejamento), na CEPAL, no Chile. Ao contrário daqueles que se dizem "economistas de esquerda", mas que perderam a capacidade crítica, Rangel nunca deixou de pensar dialeticamente. Do mesmo modo, sem menosprezar a importância do mercado, jamais se deixou influenciar pelas teses dos "fundamentalistas do mercado", tão em voga nos dias de hoje ${ }^{39}$.

Achar um rótulo para I. Rangel não é tarefa fácil. Não foi monetarista, porque acreditava que a moeda era passiva - o governo, ao emitir moeda, apenas sancionava a inflação. Tampouco era estruturalista, porque achava que o aumento dos preços era causado pela estrutura oligopolizada de comercialização de produtos agrícolas e não pela incapacidade da agricultura aumentar a oferta. Sequer foi keynesiano, porque demonstrou que, no longo prazo, a inflação tinha uma relação inversa (ao invés de direta) com o crescimento, coisa não admitida pelos compêndios

\footnotetext{
${ }^{37}$ Ignácio Rangel já pensava globalmente numa época em que a globalização ainda não fazia parte da agenda dos economistas.

${ }^{38} \mathrm{Na}$ verdade, Rangel aspirava a que os jovens seguissem adiante com o seu trabalho. No prefácio do livro Ciclo, tecnologia e crescimento (1982, p. 11), escreveu: “[...] de algum modo é mister comprometer os quadros jovens nesta empreitada, e quem sabe se eles não encontrarão motivo de realização pessoal aplicando-se a desmantelar os esquemas do 'velho Rangel'”.

39 "A suposição de que o capitalismo brasileiro esteja a caminho de recompor a competição perfeita [...] não tem coisa alguma que a corrobore” (Rangel, 1985a, p. 81).
} 
de macroeconomia de sua época ${ }^{40}$. Usava categorias de análise comuns ao materialismo histórico, mas via o socialismo com ressalvas. Foi um heterodoxo muito antes de essa palavra entrar na moda. Ele próprio se definia como uma economista de esquerda, mas essa expressão não tem o significado hoje que tinha naquela época. Chega-se à conclusão que nenhum rótulo "cola" em I. Rangel. Por quê? Porque simplesmente talvez ele sido o mais original dos nossos pensadores econômicos ${ }^{41}$.

\section{REFERÊNCIAS BIBLIOGRÁFICAS FOLHA DE SÃO PAULO}

BIELSCHOWSKY, Ricardo (1996) Pensamento Econômico Brasileiro. Rio de Janeiro: Contraponto. BRESSER-PEREIRA, Luiz Carlos e José Márcio Rego (1993), "Um mestre da economia brasileira: Ignácio Rangel”, Revista de Economia Política, v. 13, n. 2 (50), abril-junho/1993.

CARDOSO DE MELLO, J.M. (1982) O capitalismo tardio. São Paulo: Brasiliense.

CASTRO, Antonio Barros de. (1985) A economia brasileira em marcha forçada. Rio de Janeiro: Paz e Terra.

CONCEIÇÃO TAVARES, Maria da (1974) Da substituição de importações ao capitalismo financeiro. Rio de Janeiro: Zahar.

Folha de São Paulo (1994) “Economista Ignácio Rangel morre no Rio”, São Paulo, 5 março 1994.

FURTADO, Celso (1985) Formação Econômica do Brasil, 20ª edição, São Paulo: Cia. Editora. Nacional.

KALECKI, Michal (1983) Teoria da Dinâmica Econômica. Coleção “Os Economistas”. São Paulo: Abril Cultural.

PEREIRA, José Maria Dias (1984) “A participação da alimentação na inflação brasileira nos anos 70". Porto Alegre: FEE, 1984 (Série “Teses”, n.7).

PEREIRA, José Maria Dias (1993) “Os trinta anos de A Inflação Brasileira de Ignácio Rangel”, Revista de Economia Política, v. 13, n. 3 (51). julho-set./1993.

RANGEL, Ignácio Mourão (1962) “A inflação brasileira”. In: Inflação e Desenvolvimento. Rio de Janeiro: Vozes (extraído de "Econômica Brasileira", abril/junho).

RANGEL, Ignácio Mourão (1978) A inflação brasileira. 1963. 3ª ed. São Paulo: Brasiliense.

RANGEL, Ignácio Mourão (1980) Recursos ociosos e política econômica. São Paulo: Hucitec.

RANGEL, Ignácio Mourão (1981) “A questão financeira”, Revista de Economia Política, v. 1, n. 1. janeiro-março.

RANGEL, Ignácio Mourão (1981) "A história da dualidade brasileira”, Revista de Economia Política, v. 1, n. 4. outubro-dezembro.

RANGEL, Ignácio Mourão (1982) “O Brasil na fase "b" do $4^{\circ}$ Kondratieff”, In Ciclo, tecnologia e crescimento. Rio de Janeiro: Civilização Brasileira.

RANGEL, Ignácio Mourão (1982a.) "A síndrome da recessão brasileira” In: Ciclo, tecnologia e crescimento. Rio de Janeiro: Civilização Brasileira.

\footnotetext{
${ }^{40}$ O fenômeno da "estagflação" só passou a fazer parte dos manuais de macroeconomia a partir da contribuição de Milton Friedman e Edmund Phelps (final dos anos 1960), que incorporaram as expectativas de inflação na análise tradicional da curva de Phillips, demonstrando que o trade-off entre inflação e desemprego só ocorre no curto prazo. No longo prazo, quando os agentes "adaptam as suas expectativas”, a política macroeconômica é ineficaz. Ver Sachs-Larrain (2000).

${ }^{41}$ A primeira frase de um artigo de Bresser-Pereira reforça a minha conclusão: "Ignácio Rangel é provavelmente o mais original analista do desenvolvimento econômico brasileiro. Apenas Celso Furtado tem uma contribuição comparável na análise da dinâmica de nossa economia" (Bresser-Pereira, 1993, p. 98).
} 
RANGEL, Ignácio Mourão (1982b) “O direitismo da esquerda”. In: Ciclo, tecnologia e crescimento. Rio de Janeiro: Civilização Brasileira.

RANGEL, Ignácio Mourão (1982c) “A questão financeira”. In: Ciclo, tecnologia e crescimento. Rio de Janeiro: Civilização Brasileira.

RANGEL, Ignácio Mourão (1984) “Dualidade e ciclo longo”, Revista de Economia Política, v. 4, n. 1 janeiro-março.

RANGEL, Ignácio Mourão (1985) “Recessão, inflação e dívida externa”, Revista de Economia Política, v. 5 , n. 3. julho-setembro.

RANGEL, Ignácio Mourão (1985a) Milagre e Anti-Milagre. Rio de Janeiro: Jorge Zahar,

RANGEL, Ignácio Mourão (1990) “O quarto ciclo de Kondratiev”, Revista de Economia Política, v. 10, n. 4. outubro-dezembro.

SACHS, Jeffrey e Felipe B. LARRAIN, (2000) Macroeconomia em uma economia global. São Paulo: Pearson.

SUNKEL, Osvaldo (1957) “Um esquema geral para análise da inflação", In: Inflação e Desenvolvimento. Rio de Janeiro: Vozes (extraído de "Econômica Brasileira”, julho/dez. 1957). 